\title{
Multi Effect Evaporator Design Calculation for Brown Sugar Production using Computational Fluid Dynamics
}

\author{
Bambang Dwi Argo, Angky Wahyu Putranto, Anggi Lestari, Faisal Ramadhan, Rama Okatavian, \\ Randy Cahya Wihandika
}

\begin{abstract}
The industrial brown sugar production process is commonly started from grinding, filtering, first heating, sulfuric acid addition, decantation, and evaporation. Evaporation process is essential process stage in the production of brown sugar. The use of Multiple Effects Evaporator (MEE) has been becoming more common and plays an important role in the food industry, especially for producing high quality agricultural products. Therefore, several design parameters of MEE should be carefully considered such as pressure, temperature, and flow velocity. This study discusses the semi-iterative design of triple effect of feed forward system MEE for industrial-scale and simulation using Computational Fluid Dynamics (CFD). This study successfully determine the optimum value for the MEE parameters in the manufacture of brown sugar and also compared with Ms.Excel-Solver simulation. The CFD simulation indicates an accurate design process that can be employed to determine the effect of pressure, temperature, and flow velocity for MEE performance optimization.
\end{abstract}

Keywords: Multiple effects evaporator; design; brown sugar; computational fluid dynamics.

\section{INTRODUCTION}

Sugar cane juice is the raw material for sugar production in the form of liquid produced from the juice of sugar cane stems. On a large-scale industrial sugar cane roomie is the raw material for sugar production, which becomes the most demanded daily needs in the upcoming years. Sugar cane juice can be processed into other food processing products such as brown sugar which is usually operated by small and middle industries. Brown sugar can be obtained by evaporating the water contained in the sugar cane. The

Revised Manuscript Received on January 5, 2020.

* Correspondence Author

Bambang Dwi Argo*, Bioprocess Engineering, Faculty of Agricultural Technology, Universitas Brawijaya, Malang, Indonesia.

Email: dwiargo@ub.ac.id

Angky Wahyu Putranto, Bioprocess Engineering, Faculty of Agricultural Technology, Universitas Brawijaya, Malang, Indonesia.

Email: angkywahyu@ub.ac.id

Anggi Lestari, Agricultural Engineering, Faculty of Agricultural Technology, Universitas Brawijaya, Malang, Indonesia.

Email: anggilestari3131@gmail.com

Faisal Ramadhan, Agricultural Engineering, Faculty of Agricultural Technology, Universitas Brawijaya, Malang, Indonesia.

Email: faisal261198@gmail.com

Rama Otavian, Chemical Engineering, Faculty of Engineering, Universitas Brawijaya, Malang, Indonesia. Email: rama.oktavian@ub.ac.id

Randy Cahya Wihandika, Informatics Engineering, Faculty of Computer Science, Universitas Brawijaya, Malang, Indonesia.

Email: rendicahya@ub.ac.id formation of the color of brown sugar is influenced by two factors, namely the condition of the gum influenced by its chemical composition and the manufacturing process. There are several process parameters needs to be considered for brown sugar production process from sugar cane, such as the process temperature, stirring during cooking, as well as the cleanliness of the process, and the equipment used.

In conventional process of brown sugar production, process operator commonly could not control the temperature and mixing process accurately which can affect the quality of the product. In addition, the conventional processing production capacity is usually small so that much gum will undergo chemical composition changes that makes it difficult to be processed into brown sugar. The energy required in the conventional process is high both for cooking fuel or energy for cooking by humans. For this reason, a technology transfer is needed for more efficient brown sugar processing from by using an evaporator. By using evaporator, the operating temperature can be adjusted and maintained, thus it can produce more uniform size of brown sugar compared to conventional processing.

The design of multiple effect evaporator (MEE) will be complicated since its various calculation variables and iteration process involved so that we need a computational tool to simplify the calculation process. Several studies has shown the MEE design calculation phase by using Visual Basic Software with some simplifications [1] and also using Microsoft Excel and Excel Solver as non-iterative methods for MEE design with forward-feed schemes [2].

Short tube vertical evaporator with a feed-forwarded work scheme is the type of evaporator that is commonly used in the sugar cane juice evaporation process. This type uses natural circulation for its heat transfer mechanism. The circulation rate of this type is greater than the rate of input which is influenced by the heat exchanger [3]. The determination of the heater size will become important to ensure that mother liquor flows from the top of the evaporator to the bottom of the evaporator. This type of evaporator is relatively inexpensive and can be used for non-viscous solutions which have high coefficient of heat transfer and non-crystal liquids. Due to the poor circulation of liquid in this type of evaporator, this type is not suitable for liquids with high viscosity. In almost all cases, this type of evaporator operates continuously, where the rate of input is constant and the rate of concentrate is also constant [4].

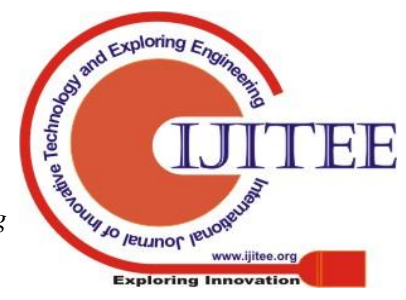


In the process of evaporation of sugarcane juice, aqueous juice with a concentration of $10-13^{\circ}$ brix is evaporated until it reaches a concentrate temperature of 40-60 ${ }^{\circ}$ brix. This paper aims to present the process of calculating MEE designs using three effects with a feed-forwarded work scheme using solidworks software which is then simulated using computational fluid dynamic.

\section{MATERIAL AND METHOD}

\section{A. Multiple Effect Evaporators Process Simulation}

In this study, the solidworks 2017 software equipped with solidworks simulation add-ins was used to design multiple effect evaporators. The process steps of fluid flow simulation in a multiple effect evaporator are as follows:
1. Designing multiple effect evaporator images in solidworks with dimensions that have been determined through manual calculations

2. Enabling computational fluid dynamic simulation on Add-ins in solidworks

3. Making a create lids at the input and output of each evaporator vessel

4. Determine the computational domain of the design we want

5. Set the boundary condition of the design that has been made namely the flow velocity, temperature, and pressure

6. Set the goals namely roomie with concentration $(x)=0,6$

7. Running program is carried out to get the values you want to know

An example of a fluid flow simulation activity in a multiple effect evaporator can be seen in Figure 1.

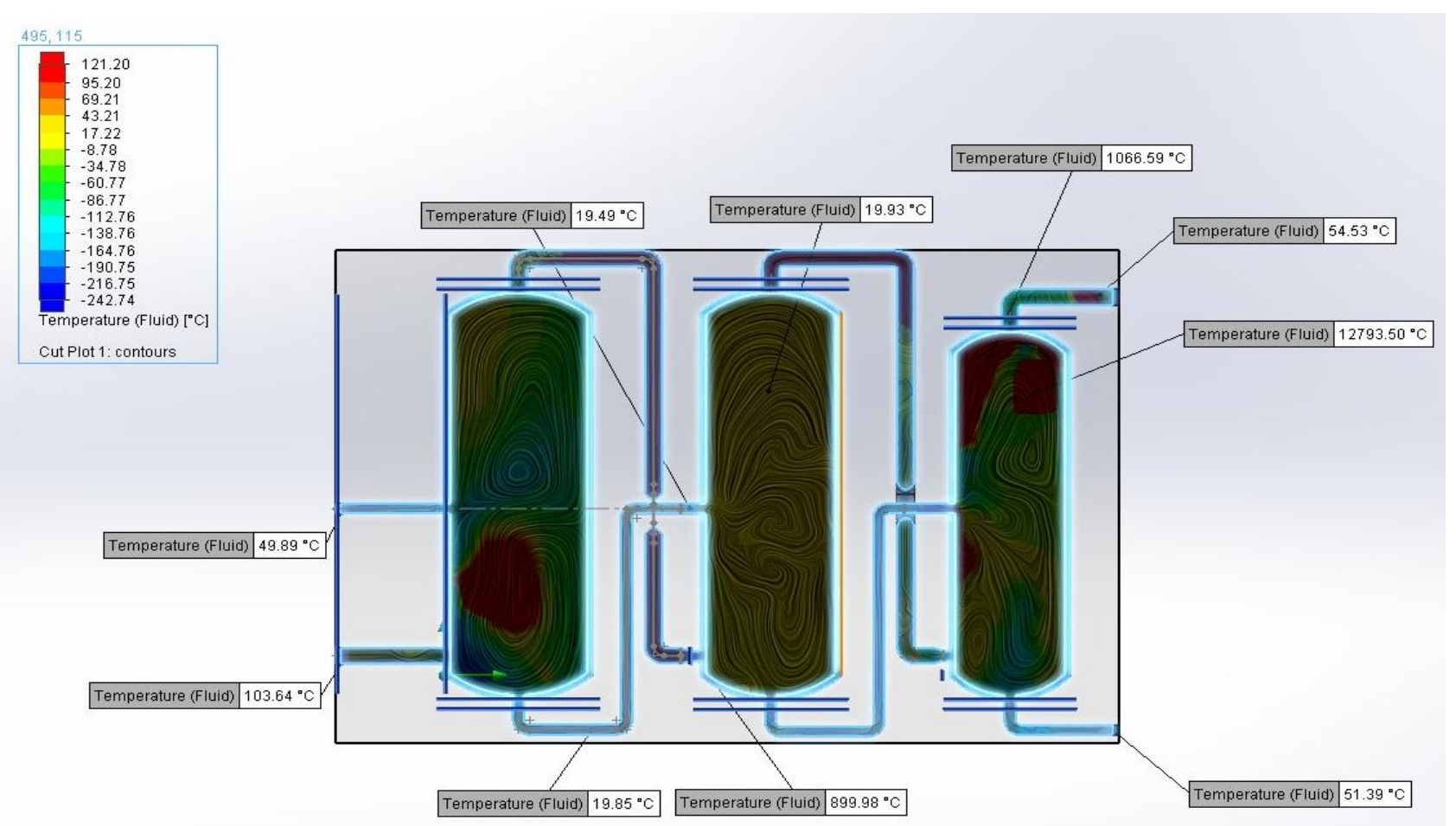

Fig. 1. Simulation Process on Multiple Effect Evaporator using Computational Fluid Dynamic

\section{B. Multiple Effect Evaporators Calculation}

In calculating the design of multiple effect evaporators there are 7 stages that must be performed [4]. The steps for calculating multiple effect evaporators according to literature are as follows:

1. Determining the boiling point on the last effect based on the desired concentration of the product and the pressure on the last effect

2.Determining the total amount of water vapor evaporated by the whole mass equilibrium process. Assuming that V1 = V2 = V3 (obtained L1, L2, L3)

3. Estimating the temperature drop from effect 1 to effect 3

4. Using heat and mass balance in each effect, calculating the evaporated fluid and fluid flow in each effects

5. Calculating the value of heat transfer in each effect and calculate the average value of the surface area for heat transfer in each effect, if the area is much different in each effect then proceed in the second iteration

6. Starting the second iteration with different $\mathrm{V}$ and $\mathrm{L}$ values (BRP prediction) is calculated starting from the fourth step until the heat transfer surface area obtained for each effect is not much different

7. Calculating the area of heat transfer in each new effect The examples of manual calculations based on the [4] Method. In this example calculation the case study is used for the MEE of three effects with a feed-forward scheme so that the calculation results that refer to the textbook can be used to validate the calculation results using computational fluid dynamic simulation. In calculations using computational fluid dynamic simulations the formulas used for calculations are input when setting desired goals in solid works.

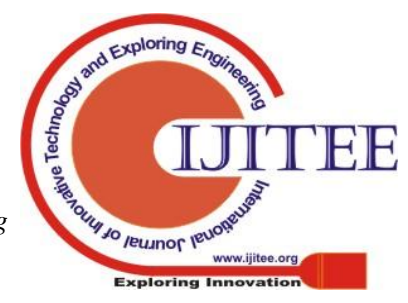


While the parameters that are refuted for the speed of behavior are flow velocity, temperature and pressure. The calculation results obtained from the simulation are then validated using the results of manual calculations in accordance with the literature.

\section{RESULT AND DISCUSSION}

\section{A. Multiple Effect Evaporators Process Simulation}

Initial conditions inputted on this simulation are thermodynamic parameters with a temperature of $50^{\circ} \mathrm{C}$ and a static pressure of $29.80 \mathrm{lbf} / \mathrm{in}^{2}$, and with a material parameter that is a type of stainless steel 302 with a material temperature of $20.05^{\circ} \mathrm{C}$. Thermodynamic parameters that are inputted as boundary conditions are the input mass flow temperature of $50^{\circ} \mathrm{C}$ with a pressure of $14.70 \mathrm{lbf} / \mathrm{in}^{2}$ and the mass flow temperature of the steam input of $121.20^{\circ} \mathrm{C}$ with a pressure of $29.80 \mathrm{lbf} / \mathrm{in}^{2}$. Figure 2 shows the simulation results of roomie for multiple effect evaporators using computational fluid dynamic.

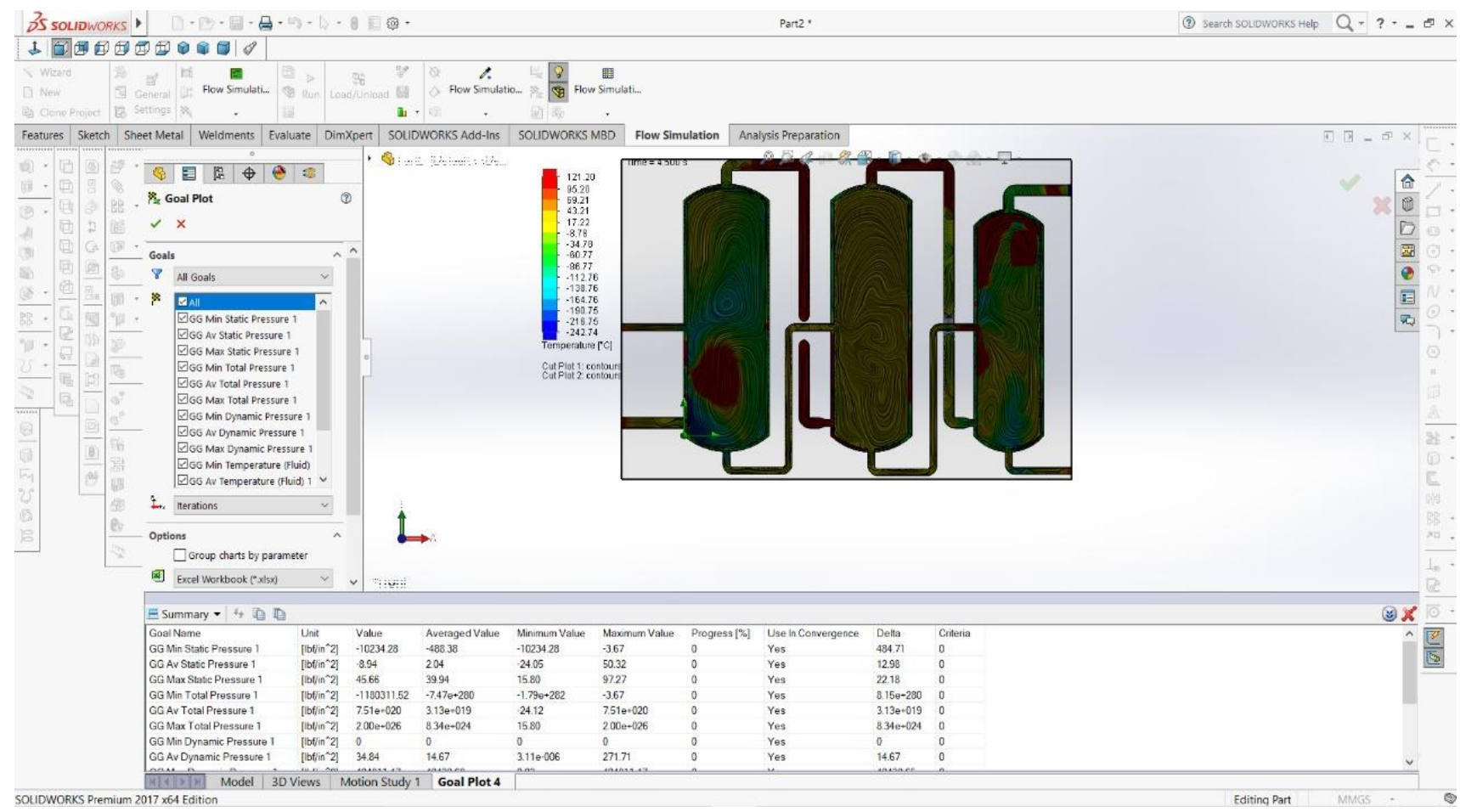

Fig. 2. Results of Simulation on Multiple Effect Evaporator

\section{B. Process Simulation Result}

Fluid is simulated until it converges on a multiple effect evaporator so that to achieve convergence 24 iterations are obtained in the simulation. From the 24 iterations, there are minimum values, maximum values, and average values presented in Table 1 obtained from the results of each iteration during the simulation process. The simulation process is carried out from the beginning of the input of material in effect 1 and the output of material in effect 3 so that the values presented in Table 1 are the total values obtained from the three effects used.

Table- I: Results of parameters simulation

\begin{tabular}{|c|l|c|c|c|c|}
\hline $\begin{array}{c}\mathbf{N} \\
\mathbf{o}\end{array}$ & Parameters & Units & Min Value & Max value & $\begin{array}{c}\text { Average } \\
\text { value }\end{array}$ \\
\hline 1 & Flow velocity & $\mathrm{lb} / \mathrm{hr}$ & $7.488 \times 10^{-4}$ & 1586.698 & 138.452 \\
\hline 2 & Temperature & ${ }^{\circ} \mathrm{C}$ & 20.042 & 199.206 & 35.867 \\
\hline 3 & Pressure & $\mathrm{lbf} / \mathrm{in}^{2}$ & -24.118 & $7.513 \times 10^{20}$ & $3.131 \times 10^{19}$ \\
\hline
\end{tabular}

Table 2 presents the simulation results using the CFD Add-ins and the test results using an excel-add solver from previous study [2]. The flow velocity optimum value by using CFD simulation has an error of $15.24 \%$ if compared with excel-solver simulation. This is influenced by the evaporation temperature which is slightly lower than the evaporation temperature. So that it affects the viscosity of the fluid which causes the fluid flow velocity to decrease. The higher the evaporation temperature of brown sugar the hedonic quality scale value associated with the hardness of brown sugar produced the better [5].

Table- II: Comparison the optimum result

\begin{tabular}{|l|l|c|c|c|}
\hline No & Parameters & Units & CFD Simulation & $\begin{array}{c}\text { Excel-solver } \\
\text { Simulation [2] }\end{array}$ \\
\hline 1 & Flow velocity & $\mathrm{lb} / \mathrm{hr}$ & 325.402 & 375 \\
\hline 2 & Temperature & ${ }^{\circ} \mathrm{C}$ & 51.39 & 54.97 \\
\hline 3 & Pressure & $\mathrm{lbf} / \mathrm{in}^{2}$ & 0.04 & 1.94 \\
\hline
\end{tabular}

Based on Table 2, there is a difference in the temperature parameter by using CFD simulation or has an error around $7 \%$ if compared with excel-solver simulation. This difference occurs due to the fluid convergence process in the MEE so that there is no heat absorption by the MEE which affects the fluid output temperature in the third effect is smaller than the results of previous studies [2].

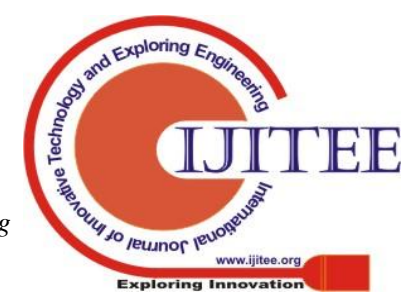


The last parameter is pressure, which has significant value of pressure compared with excel-solver simulation. A significant difference in value between the two simulation methods used is also indirectly influenced by the temperature used. The low temperatures will also affect the pressure produced. However, based on the results of the program validation with manual counts in the textbooks it was found that the program that was made with solidworks produced the calculations as desired. Both Solid works with CFD add-ins and Ms. Excel-solver can be used easily for MEE design calculations. The use of Add in steam tables will greatly simplify the calculation process so that in the calculation it is not necessary to see the steam table repeatedly manually [2]. The use of Excel-Solver and solidworks-CFD can be a non-iterative calculation solution for estimating Boiling Point Rise and for estimating the detailed heat exchanger size in order to optimize of MEE performance.

\section{CONCLUSION}

The computational simulation validation with a manual calculation in the literature, it was found that the simulation results using computational fluid dynamic are in well agreement with the desired results. The simulation process is carried out until the fluid converges in a multiple effect evaporator with $24^{\text {th }}$ iterations so that the minimum and maximum values of temperature, pressure and flow velocity can be determined as the testing parameters. There is an error value between the CFD simulation results and excel-solver simulation result since the fluid process for convergence that affects the product output temperature, pressure, and product flow rate with the concentration of thick liquid brown sugar equal to 0.6. The CFD simulation process for evaporator size determination was carried out until the $24^{\text {th }}$ iteration to obtain small deviation. By using the computational fluid dynamic software, an accurate design process can be performed to determine the effect of parameters in order to optimize of MEE performance.

\section{ACKNOWLEDGMENT}

The authors would like to thank the institute of research and community services of Universitas Brawijaya through dedicated doctoral program funding 2019.

\section{REFERENCES}

1. A. J. Cudier, and C. O. Fuentes, "A simplified and generalized method to size multiple-effect evaporator systems with any feed scheme", $2^{\text {nd }}$ Mercusor Congress on Chemical Engineering, $4^{\text {th }}$ Mercusor Congress on Process System Engineering, Costa Verde, Rio de Janeiro-Brazil, 2005.

2. D. F. Al Riza, M. B. Hermanto, B. D. Argo, "Desain multi effect evaporator dengan menggunakan excel add-in dan solver", Prosiding Seminar Nasional PERTETA, December 2012, pp. 1-6 (in Indonesian).

3. E. A. Gloria, "Pengaruh ${ }^{\circ}$ brix terhadap karakterisitik perpindahan panas pada evaporator robert sistem quintuple-effect di PG. Gempolkrep, Jurnal Teknik ITS, vol. 5, no. 1, 2016 (in Indonesian).

4. C. J. Geankopolis, "Transport Processes and Unit Operation", $3^{\text {rd }}$ edition, New Jersey, Prentice Hall Inc, 1978.

5. S. R. Dewi, N. Izza, D. A. Agustiningrum, D. W. Indriani, Y. Sugiarto, D M. Maharani, R. Yulianingsih, "Pengaruh suhu pemasakan nira dan kecepatan pengadukan terhadap kualitas gula merah tebu", Jurnal Teknologi Pertanian, vol. 15, no.3, pp. 149-158, 2014 (in Indonesian).

\section{AUTHORS PROFILE}

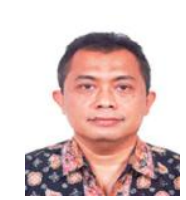

Bambang Dwi Argo, is the associate professor who teaches in the Bioprocess Technology Study Program, Faculty of Agricultural Technology, Universitas Brawijaya since 33 years ago. As a Senior Lecturer, he is very active in research and community service activities. He has also published several books, has many publications and patents in the field of Agricultural Engineering Modelling and Bioenergy, and as a keynote speaker on various scientific activities in Indonesia.

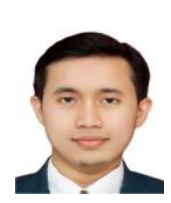

Angky Wahyu Putranto, is a young lecturer who teaches in the Bioprocess Technology Study Program, Department of Agricultural Engineering, Faculty of Agricultural Technology, Universitas Brawijaya since 5 years ago. He is also active in research activities in the field of downstream bioprocess optimization.

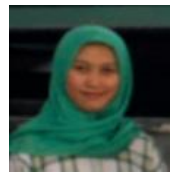

Anggi Lestari, is a student in the Department of Agricultural Engineering, Faculty of Agricultural Technology, Universitas Brawijaya. She is also active in the student organizations activities and community service.

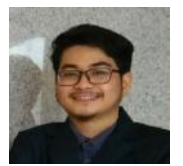

Faisal Ramadhan, is a student in the Department of Agricultural Engineering, Faculty of Agricultural Technology, Universitas Brawijaya. He is also active in the student organizations activities and community service.

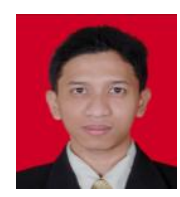

Rama Oktavian, is a young lecturer who teaches in the Chemical Engineering Department, Faculty of Engineering, Universitas Brawijaya since 7 years ago. He is also active in thermodynamics and phase equilibrium.

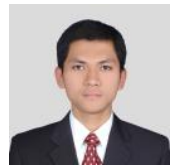

Randy Cahya Wihandika, is a young lecturer who teaches in the Informatics Engineering Department, Faculty of Computer Science, Universitas Brawijaya since 6 years ago. $\mathrm{He}$ is also active in research activities in the field of image processing and computer vision. 